\title{
Cranial nerves XIII and XIV: nerves in the shadows
}

This article was published in the following Dove Press journal:

Journal of Multidisciplinary Healthcare

12 March 2013

Number of times this article has been viewed

\author{
Bruno Bordoni' \\ Emiliano Zanier ${ }^{2}$ \\ 'Don Carlo Gnocchi IRCCS, \\ Department of Cardiology, Milan, \\ ${ }^{2}$ Xamar Institute, Rosà, Vicenza, Italy
}

Correspondence: Bruno Bordoni Department of Cardiology, Don Carlo Gnocchi IRCCS, Via Capecelatro 66, Milan, Italy

Tel +393496300617

Email bordonibruno@hotmail.com
Abstract: It has been known for over a century that these cranial nerves exist, and that they are not typographical errors nor a sensational event reported in the medical literature. A number of scientific articles on anatomy highlight how textbooks on descriptive anatomy do not always consider variables such as differences related to the geographical areas where people live, and these differences do exist. This is an important concept not only for surgeons, but also for all medical professionals who use manual techniques when treating their patients, ie, osteopaths, chiropractors, physiotherapists, and other manual therapists. This paper highlights the latest developments regarding these cranial nerves, offering at the same time some ideas for further reflection when looking at clinical scenarios that appear to bear little relationship to each other. Inclusion of these concepts in everyday anamnesis is encouraged.

Keywords: cranial nerve, facial nerve, trigeminal system, Tolosa-Hunt syndrome

\section{Introduction}

Cranial nerve XIII is also known as the "zero nerve" or "nerve N". First discovered in 1870 in sharks and other types of fish, it was initially referred to as the nerve of pinkus. In 1905, it became classified as terminal because, in other animal species, it was observed to extend into the region of the lamina terminalis (delineating the anterior wall of the third ventricle and, in its lower section, before the optic chiasma, forming the optic recess). ${ }^{1}$ From an osteopathic perspective, this area can develop into a dysfunction point with regard to cranial kinetics, with different clinical presentations. ${ }^{2}$ This gives us an insight into the importance and complexity of this nerve. Recent textbooks, published after 1987, have classified cranial nerve XIII as the zero nerve, given that it is more rostral than the other cranial nerves. Although first formally mentioned in a paper on human anatomy in $1945,{ }^{1}$ it has rarely been mentioned in the medical literature since. The probable reason for this is that, during anatomical dissection, when taking off the dura mater, this nerve is torn off and cannot be found on subsequent examination. However, as long as the pia mater remains intact, the nerve can be located between the olfactory stalk and the rostral section of the optic chiasma. ${ }^{1}$ The nerve is attached to the pia mater by connective tissue, ${ }^{1}$ and this concept is useful for osteopaths in order to link dysfunction of the nerve to craniosacral movement.

Cranial nerve XIV was first identified in 1563, but it was not until 1777 that it was mentioned in a textbook as the nerve of Wrisberg. ${ }^{3}$ In modern textbooks, it is referred to as the nervus intermedius or "intermediary nerve". ${ }^{3}$ Its name is consistent with its intermediary location between the facial nerve (cranial nerve VII) and the superior section of the vestibulocochlear nerve (cranial nerve VIII). ${ }^{4}$ It is well known to cause 
otalgia and related surgical operations. This confirms that this nerve is an independent entity and not a mere ramification of cranial nerve VII.

\section{Nerve $\mathbf{N}$}

Anatomy is still a field rich in findings, and as regards the data collected so far, nothing can be taken for granted. There are many reference texts on anatomical dissection that demonstrate numerous variations in the human body..$^{5-8}$ In humans, nerve $\mathrm{N}$ is composed of a small tract of nerves with nonmyelinated fibers. Unlike the other cranial nerves, nerve $\mathrm{N}$ lies in the most rostral area where the brainstem and olfactory bulb are located. ${ }^{1}$ Nerve N passes through the medial region of the stria olfactoria (ie, medial in relation to the anterior perforated space) and, via the rectus gyrus of the orbital surface of the frontal lobe, reaches the crista galli laterally. Finally, it passes through the cribriform plate of the ethmoid bone more medially and deeply than do the tracts of the olfactory nerve..$^{1,9,10}$ Nerve $\mathrm{N}$ is very thin in adults but is easily identifiable in the fetal stage. ${ }^{1}$ It has a small ganglion, with other as yet unidentified afferents, ${ }^{1}$ indicating that it might have some residual function to warrant consideration in diagnosis and treatment. As demonstrated by research in other species, the nerve is linked with the olfactory nerve ${ }^{11}$ in terms of its location and probably also its function. From an embryological perspective, it seems to have developed from the area of the olfactory cells, although some have hypothesized that it may originate from the neural crest. ${ }^{12}$ In any case, it would derive from the ectoderm. ${ }^{13}$ Other textbooks assume it is related to the nasopalatine nerve, either directly or through the sympathetic trunk. It is important to remember that, at the level of the nose, there is the nasopalatine nerve which innervates the nasal cavity and belongs to the maxillary section of the trigeminal nerve. At the same level there is the ethmoidal nerve, which supplies the anterior nasal mucosa, and develops from the ophthalmic division of the trigeminal nerve. ${ }^{14}$ Interestingly, this nerve is connected to small blood vessels, ${ }^{1}$ meaning that it could have direct contact with the entire body. Furthermore, in some animal species, nerve $\mathrm{N}$ supplies the retina, indicating that this nerve may be responsive to light. ${ }^{15}$

So far, there are still differing opinions about the function of this nerve. However, these are only hypotheses and suggestions, none of which is definitely based on incontrovertible evidence. ${ }^{16}$ Nonetheless, speculation is possible when considering what the medical literature offers at present. According to the numerous studies carried out to date, nerve $\mathrm{N}$ could somehow be connected with reproductive function.
In several animal species, nerve $\mathrm{N}$ secretes or stimulates the secretion of luteinizing hormone-releasing hormone, also known as gonadotropin-releasing hormone. ${ }^{1,12,17}$ This hormone coordinates the hypothalamus-pituitary-gonadal axis. ${ }^{18,19}$ In animals, this nerve can be located without difficulty, and its functions are more evident, ie, it is presumed to control sexual behavior and reproductive activity. ${ }^{20-23}$ Stimulation of nerve $\mathrm{N}$ is believed to trigger a series of hormonal cascades from the nasal region to the reproductive system. ${ }^{11,24,25}$ Therefore, one hypothesis is that nerve $\mathrm{N}$ might trigger an endocrine response, directly or jointly with other nerve structures, such as the kisspeptin neural network. In humans, particularly in females, this group of neurons can be identified as being mainly in the preoptic area and in the infundibular nucleus of the mediobasal hypothalamus. ${ }^{26}$ Could this mean that women may be more affected by nerve N? We still do not know. Undoubtedly, a woman's sense of smell is stronger during ovulation. ${ }^{1}$ Moreover, in the human model, the area in question is a source of interest regarding sexual behavior, although there are no decisive writings on this topic. ${ }^{27}$

Generally speaking, stimulation of a hormonal response in men can be linked with the nasal epithelium (through chemosensitive receptors or unidentified bonds with pheromones). ${ }^{22,28-30}$ Research in humans shows that nerve $\mathrm{N}$ is directly connected to the limbic system, at least in the fetus, and consequently to the olfactory system. ${ }^{1}$ Further studies in the human model suggest that this nerve has the ability to store small polypeptides, including luteinizing hormonereleasing hormone, acetylcholine, and neuropeptide Y. ${ }^{1}$ The latter can also be found in the amygdala, with a number of functions in influencing behavior, including nociception. ${ }^{31}$

The current view is that nerve $\mathrm{N}$ has the ability to affect sexual behavior, but the extent to which it does this is unknown as yet. It is believed to act by stimulating luteinizing hormone-releasing hormone on contact with pheromones, improving olfaction and identifying odors, and this series of events will affect sexual behavior. ${ }^{1}$ Nerve $\mathrm{N}$ is suggested to have afferents that originate from the sympathetic ganglia of the superior cervical tract, or from the pterygopalatine ganglion. ${ }^{1}$ Undeniably, these are interesting hypotheses, but await verification. Finally, the trigeminal system can be stimulated by odors. ${ }^{14,32}$ If a connection between the cervical sympathetic ganglia, the trigeminal system, and the aforementioned nerve was confirmed, we might better understand and explain some cervical disorders, such as those related to the menstrual cycle or chronic rhinitis. In addition, we could link certain sexual behavioral disorders to trigeminal pain. 
Many other hypotheses might be formulated, but what is certain is that the human body is a sole entity. In order for the body to maintain homeostasis, each and every part needs to be in harmonious and tensegritive collaboration, with regard to not only fascial but also immunological, neuroendocrine, and psychological functioning. Recent research on the olfactory system theorizes a correlation between olfactory changes and certain psychiatric and behavioral disorders, and other neurological pathologies. ${ }^{33-35}$ Recently, some scientific articles have been published suggesting that the olfactory sense is a survival tool and essential for enabling attention in conscious individuals. ${ }^{36}$ A possible connection between the olfactory nerve and nerve $\mathrm{N}$ offers further clinical scenarios. However, we are again awaiting further research on this relationship.

\section{Intermediary nerve}

The intermediary nerve has always been considered a ramification of the facial nerve, which is complex ${ }^{37,38}$ and all its connections have not been clearly revealed as yet. However, the intermediary nerve is actually a separate and independent nervous entity. ${ }^{39,40}$ One study has demonstrated at autopsy that this nerve has four different anatomical origins: the brainstem, where it is evident as a tract of nerve fibers; the top of cranial nerve VII; the top of cranial nerve VIII; and finally, multiple sites in the greater area of the brainstem. ${ }^{39}$ According to this study, its ramifications are between 2 and 5, not 4 as we have always thought. ${ }^{39}$ It comprises visceral efferents comprised of preganglionic and parasympathetic fibers, which involve the submandibular and sublingual lacrimal glands as well as minor salivary glands. It is a short nerve, measuring no more than $21 \mathrm{~mm}$ in length. ${ }^{40,41}$ These efferents contact the pterygopalatine ganglion and pass through the base of the pterygoid process of the sphenoid bone, then extend into the pterygoid (vidian) canal, finally reaching the pterygopalatine fossa and developing synaptic connections with the homonymous ganglion. ${ }^{40}$ Another portion of these preganglionic and parasympathetic efferents reaches the geniculate ganglion in the middle ear through a pathway that runs in parallel with the motor component of cranial nerve VII, and finally arrives at the tympanic section and the chorda tympani nerve, which develops from the facial nerve. ${ }^{40,42}$

In contrast, the afferents of the intermediary nerve derive from receptors known as the concha auriculae located in a small area behind the ear, from the external layer of the membrana tympani, and from part of the wall of the external auditory meatus. ${ }^{40}$ Moreover, some afferents develop from the taste receptors on the anterior two thirds of the tongue, from the floor of the mouth and palate, from the nasal mucosa and nasopharynx (presumably because of the connection with the lingual nerve, a branch of the mandibular division of the trigeminal nerve); and finally, from the chorda tympani nerve that branches from the facial nerve. ${ }^{3,40}$ Most textbooks report that this nerve has a sensory function, yet motor efferents of this nerve have also been identified, and electrophysiological studies carried out during surgery on patients have revealed that stimulation of this nerve can result in contraction of the orbicularis oris muscle, which has four segments. This has further confirmed its separation from the facial nerve. ${ }^{3}$

From an anatomical perspective, which involves taking into consideration its direct connections with the geniculate nucleus, the pterygopalatine ganglion, and the brainstem, and from an electrophysiological point of view, the intermediary nerve is now regarded as a nervous structure in its own right. ${ }^{3}$ This prompts some interesting considerations. First, the intermediary nerve is connected indirectly to the trigeminal system. ${ }^{40}$ Moreover, when it comes into contact with the chorda tympani nerve, the two nerves become one and the same, and then, passing through the petrotympanic fissure, the intermediary nerve becomes an extra cranial nerve. ${ }^{4,40}$ Further research suggests that if the temporomandibular joint does not move properly for whatever reason, the pterygopalatine ganglion will be affected, and may alter the functions of the aforementioned intermediary nerve. Finally, looking more closely at the intermediary nerve, there are minute anastomoses with nerves VII and VIII at the level of their origin. ${ }^{3}$ A logical deduction is that disorders in any of these nerves may affect the physiology of the intermediary nerve and vice versa, which may alter their function.

The recent medical literature cites the intermediary nerve in terms of the problems it may cause, although these do not occur frequently. For example, paroxysmal otalgia (lasting seconds or minutes), found in combination with alterations in lacrimation, salivation, and taste perception, is known as geniculate neuralgia, neuralgia of the intermediary nerve, or Tolosa-Hunt syndrome. ${ }^{4,40,41}$ Its causes may be different, ranging from malignancy to vascular compression, but are mainly idiopathic. ${ }^{3,41,43,44}$ Finally, it is important to consider the intermediary vein, ${ }^{39}$ which is adjacent to the intermediary nerve, which may alter the electrical function of this nerve in the event of anomalous venous drainage. As osteopaths, we know that anomalous drainage of the cranial venous system may cause dysfunction in the cranial nerves. ${ }^{2}$ These data can be useful to us in order to understand and treat the symptoms mentioned in this paper. 


\section{Conclusion}

In the light of the information currently available in the medical literature, the nomenclature for the cranial nerves should be revised. Further studies are needed to improve our knowledge of the clinical scenarios that may arise from physiological alteration of their function, as well as a more detailed anatomical description of medical strategies which may be helpful in treating related problems.

\section{Acknowledgment}

In memory of Erio Mossi; osteopath, teacher, and writer.

\section{Disclosure}

The authors report no conflicts of interest in this work.

\section{References}

1. Vilensky JA. The neglected cranial nerve: nervus terminalis (cranial nerve N). Clin Anat. July 26, 2012. [Epub ahead of print.]

2. Liem T, McPartland J, Skinner E, Barral JP, Mitchell FL, Feely RA. Cranial Osteopathy. Principles and Practice, 2nd ed. Philadelphia, PA: Elsevier Churchill Livingstone; 2004.

3. Alfieri A, Strauss C, Prell J, Peschke E. History of the nervus intermedius of Wrisberg. Ann Anat. 2010;192:139-144.

4. Tubbs RS, Steck DT, Mortazavi MM, Cohen-Gadol AA. The nervus intermedius: a review of its anatomy, function, pathology, and role in neurosurgery. World Neurosurg. April 3, 2012. [Epub ahead of print.]

5. Lee SE, Jung C, Ahn KY, Nam KI. Bilateral asymmetric supernumerary heads of biceps brachii. Anat Cell Biol. 2011;44:238-240.

6. Mehta V, Suri RK, Arora J, Dave V, Rath G. Supernumerary peronei in the leg musculature - utility for reconstruction. Chang Gung Med J. 2011;34(Suppl 6):62-65.

7. Paraskevas GK, Ioannidis O, Economou DS. Anomalous muscle causing ulnar nerve compression at Guyon's canal. J Plast Surg Hand Surg. 2012;46:4288-4290.

8. Prabhu LV, Asif M, Murlimanju BV, Anup Rao K, Shivaprakash S. Anomalous fascicle of triceps brachii muscle and its clinical importance in relation to radial nerve entrapment. Clin Ter. 2012;163:123-124. Italian.

9. Fuller GN, Burger PC. Nervus terminalis (cranial nerve zero) in the adult human. Clin Neuropathol. 1990;9:279-283.

10. Ramos A, Chaddad-Neto F, Joaquim AF, et al. The microsurgical anatomy of the gyrus rectus area and its neurosurgical implications. Arq Neuropsiquiatr. 2009;67:90-95.

11. Whitlock KE. Development of the nervus terminalis: origin and migration. Microsc Res Tech. 2004;65:2-12.

12. Von Bartheld CS. The terminal nerve and its relation with extrabulbar "olfactory" projections: lessons from lampreys and lungfishes. Microsc Res Tech. 2004;65:213-224.

13. Von Bartheld CS, Baker CV. Nervus terminalis derived from the neural crest? A surprising new turn in a century-old debate. Anat Rec B New Anat. 2004;278:12-13.

14. Silver WL, Finger TE. The anatomical and electrophysiological basis of peripheral nasal trigeminal chemoreception. Ann NY Acad Sci. 2009;1170:202-205.

15. Wirsig-Wiechmann CR. Introduction to the anatomy and function of the nervus terminalis. Microsc Res Tech. 2004;65:1.

16. Wirsig-Wiechmann CR, Wiechmann AF, Eisthen HL. What defines the nervus terminalis? Neurochemical, developmental, and anatomical criteria. Prog Brain Res. 2002;141:45-58.
17. Schwanzel-Fukuda M, Garcia MS, Morrell JI, Pfaff DW. Distribution of luteinizing hormone-releasing hormone in the nervus terminalis and brain of the mouse detected by immunocytochemistry. J Comp Neurol. 1987;255:231-244.

18. Christensen A, Bentley GE, Cabrera R, et al. Hormonal regulation of female reproduction. Horm Metab Res. 2012;44:587-591.

19. Wierman ME, Kiseljak-Vassiliades K, Tobet S. Gonadotropin-releasing hormone $(\mathrm{GnRH})$ neuron migration: initiation, maintenance and cessation as critical steps to ensure normal reproductive function. Front Neuroendocrinol. 2011;32:43-52.

20. Demski LS. Terminal nerve complex. Acta Anat (Basel). 1993;148: 381-395.

21. Kawai T, Oka Y, Eisthen $H$. The role of the terminal nerve and GnRH in olfactory system neuromodulation. Zoolog Sci. 2009;26:669-680.

22. Ma M. Odor and pheromone sensing via chemoreceptors. Adv Exp Med Biol. 2012;739:93-106.

23. Oelschläger HA, Buhl EH, Dann JF. Development of the nervus terminalis in mammals including toothed whales and humans. Ann NY Acad Sci. 1987;519:447-464.

24. Schwarting GA, Wierman ME, Tobet SA. Gonadotropin-releasing hormone neuronal migration. Semin Reprod Med. 2007;25:305-312.

25. Topaloglu AK, Semple RK. Neurokinin B signalling in the human reproductive axis. Mol Cell Endocrinol. 2011;346:257-264.

26. Lehman MN, Merkley CM, Coolen LM, Goodman RL. Anatomy of the kisspeptin neural network in mammals. Brain Res. 2010;1364: 90-102.

27. Sakamoto H. Brain-spinal cord neural circuits controlling male sexual function and behavior. Neurosci Res. 2012;72:103-116.

28. Bhutta MF. Sex and the nose: human pheromonal responses. $J$ R Soc Med. 2007;100:268-274

29. Savic I, Hedén-Blomqvist E, Berglund H. Pheromone signal transduction in humans: what can be learned from olfactory loss. Hum Brain Mapp. 2009;30:3057-3065.

30. Trotier D. Vomeronasal organ and human pheromones. Eur Ann Otorhinolaryngol Head Neck Dis. 2011;128:184-190.

31. Gilpin NW. Neuropeptide Y (NPY) in the extended amygdala is recruited during the transition to alcohol dependence. Neuropeptides. 2012;46:253-259.

32. Frasnelli J, Schuster B, Hummel T. Interactions between olfaction and the trigeminal system: what can be learned from olfactory loss. Cereb Cortex. 2007; 17:2268-2275.

33. Burón E, Bulbena A. Olfaction in affective and anxiety disorders: a review of the literature. Psychopathology. 2013;46:63-74.

34. Doty RL. Olfactory dysfunction in Parkinson disease. Nat Rev Neurol. 2012;8:329-339.

35. Schecklmann M, Schwenck C, Taurines R, et al. A systematic review on olfaction in child and adolescent psychiatric disorders. $J$ Neural Transm. 2013;120:121-130.

36. Keller A. Attention and olfactory consciousness. Front Psychol. 2011;2: 380 .

37. Myckatyn TM, Mackinnon SE. A review of facial nerve anatomy. Semin Plast Surg. 2004;18:5-12.

38. Ozdoğmuş $\mathrm{O}$, Sezen $\mathrm{O}$, Kubilay U, et al. Connections between the facial, vestibular and cochlear nerve bundles within the internal auditory canal. J Anat. 2004;205:65-75.

39. Alfieri A, Fleischhammer J, Peschke E, Strauss C. The nervus intermedius as a variable landmark and critical structure in cerebellopontine angle surgery: an anatomical study and classification. Acta Neurochir (Wien). 2012;154:1263-1268.

40. Guinto G, Guinto Y. Nervus intermedius. World Neurosurg. May 24, 2012. [Epub ahead of print.]

41. Nanda A, Khan IS. Nervus intermedius and geniculate neuralgia. World Neurosurg. May 24, 2012. [Epub ahead of print.]

42. Birgfeld C, Neligan P. Surgical approaches to facial nerve deficits. Skull Base. 2011;21:177-184. 
43. Alfieri A, Fleischhammer J, Strauss C, Peschke E. The central myelinperipheral myelin transitional zone of the nervus intermedius and its implications for microsurgery in the cerebellopontine angle. Clin Anat. 2012;25:882-888.
44. Mowry S, Hansen M, Gantz B. Surgical management of internal auditory canal and cerebellopontine angle facial nerve schwannoma. Otol Neurotol. 2012;33:1071-1076.

\section{Publish your work in this journal}

The Journal of Multidisciplinary Healthcare is an international, peerreviewed open-access journal that aims to represent and publish research in healthcare areas delivered by practitioners of different disciplines. This includes studies and reviews conducted by multidisciplinary teams as well as research which evaluates the results or conduct of such teams or healthcare processes in general. The journal covers a wide range of areas and welcomes submission from practitioners at all levels, from all over the world. The manuscript management system is completely online and includes a very quick and fair peer-review system. Visit http://www.dovepress.com/testimonials.php to read real quotes from published authors.

Submit your manuscript here: http://www.dovepress.com/journal-of-multidisciplinary-healthcare-journal 